\title{
A COMPREHENSIVE ANALYSIS OF MEASURED AND COMPUTED DEPTH OF CLOSURE AROUND THE COAST OF JAPAN
}

\author{
Keiko Udo, Tohoku University, udo@irides.tohoku.ac.jp \\ Yuriko Takeda, Tohoku University, takeda@irides.tohoku.ac.jp \\ Roshanka Ranasinghe, IHE Delft/Univ. of Twente/Deltares, r.ranasinghe@un-ihe.org
}

\section{INTRODUCTION}

The Depth of closure (DoC), i.e., the depth seaward of which significant sediment transport and consequent elevation changes do not occur, is one of the most important parameters in coastal morphodynamics. The concept is widely used for estimating sediment budgets, numerical models of coastal change, beach nourishment design and disposal of dredged material. With recent interest on climate change impact assessments on coasts, the Bruun (1962) rule, in which DoC is a key parameter, is often used for future beach loss analysis (e.g., Udo and Takeda, 2017); However, the determination of DoC, especially in the absence of repeated profile measurements, is one of the controversial issues in employing the Bruun rule for such impact assessments for decision making (e.g., Ranasinghe et al., 2012).

A well-known predictive equation for DoC was proposed by Hallermeier (1978). Nicholls et al. (1998) evaluated applicability of a revised version of this equation (Eq.1) using 12 years (July 1981 to July 1993) of profile data collected at the Field Research Facility located in Duck, NC, U.S.A.

$$
D o C_{1, t}=2.28 H_{e, t}-68.5\left(H_{e, t}{ }^{2} / g T_{e, t}{ }^{2}\right) \quad \text { (Eq. 1) }
$$

where $H_{e, t}$ is the significant wave height that is exceeded only 12 hours per $t$ years, $T_{e, t}$ is the associated wave period, and $g$ is the gravitational acceleration. They concluded that Eq 1 provided robust estimates of depth of closure. The present study analyzes both measured DoCs and wave datasets at multiple beaches in Japan, and reevaluates the applicability of the Nicholls's (1998) equation.

\section{METHODS}

DoCs derived from direct field measurememts at more than 50 Japanese beaches were summarized in Uda (1996). Selected locations of study sites are shown in Figure 1. Periods of the profile or bathymetry data used to determine DoC ranges from 1 to more than 20 years since 1960s.

To compare these measured DoCs with those computed using wave data, here we employed Eq. (1). To compare the accuracy of DoCs computed on the source of wave data, here we used two sets of data: (1) 2-hourly data from the Nationwide Ocean Wave information network for Ports and HArbourS (NOWPHAS) provided by Ports and Harbours Bureau, Ministry of Land, Infrastructure, Transport, and Tourism (MLIT), and (2) 6-hourly data from the WaveWatch III reanalysis The NOWPHAS wave data has been obtained at 5 locations in 1970, 40 locations in 1990, and more than 60 locations as of 2016. Acquisition rate of the data is nearly $100 \%$ at most of the locations after 1990s.

\section{RESULTS}

The DoCs computed using Eq. 1 show good agreement with measured values at 12 beaches analyzed so far (Figure 2). The DoCs computed with reanalyzed wave data appear to be slightly less accurate compared to those computed using measured wave data.

\section{CONCLUDING REMARKS}

The results of this study shows that Nicholls's (1998) DoC equation is generally applicable at multiple beaches in Japan. At the conference, generic results based on the analysis of measured and computed DoCs at beaches all around the Japanese coast will be presented.

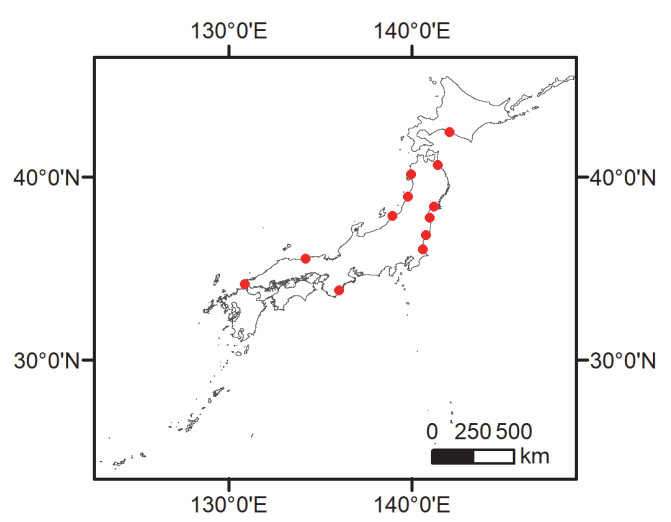

Figure 1 - Locations of selected study sites.

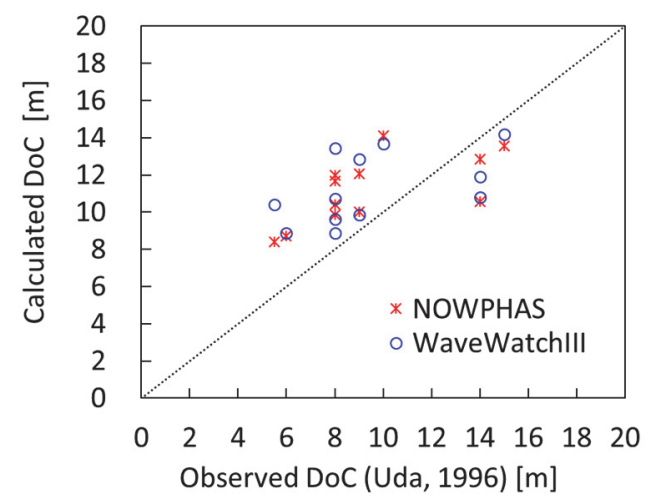

Figure 2 - Relationship between DoCs measured and computed using NOWPHAS (measured) and WaveWatch III (reanalyzed) wave data.

\section{REFERENCES}

Bruun, P. (1962): Sea-level rise as a cause of shore erosion, J. Waterways and Harbors Div., 88, pp. 117-130. Hallermeier, R.J. (1978): Uses for a calculated limit depth to beach erosion, Proc. 16th Coastal Eng. Conf., pp. 14931512.

Nicholls R.J., Birkemeier, W.A., and Lee, G. (1998): Evaluation of depth of closure using data from Duck, NC, USA, Marine Geology, vol. 148, pp. 179-201.

Ranasinghe, R., Callaghan, D., and Stive, M.J.F. (2012): Estimating coastal recession due to sea level rise: beyond the Bruun Rule, Climatic Change, vol. 110, pp. 561-574. Uda, T. (1996): Coastal erosion in Japan, 442p.

Udo, K., Takeda, Y. (2017): Projections of future beach loss in Japan due to sea-level rise and uncertainties in projected beach loss, Coast. Eng. J., vol. 59, 1740006. 